\title{
PADRÕES DE INTERCEPTAÇÃO DE RADIAÇÃO SOLAR EM VINHEDOS COM E SEM COBERTURA PLÁSTICA ${ }^{1}$
}

\author{
LOANA SILVEIRA CARDOSO ${ }^{2}$, HOMERO BERGAMASCHI $^{3}$, FLÁVIA COMIRAN ${ }^{4}$, \\ GERALDO CHAVARRIA ${ }^{5}$, GILMAR ARDUÍNO BETTIO MARODIN ${ }^{6}$, \\ GENEI ANTÔNIO DALMAGO ${ }^{7}$, HENRIQUE PESSOA DOS SANTOS ${ }^{8}$, FRANCISCO MANDELLI $^{8}$
}

RESUMO - O trabalho teve por objetivo avaliar padrões de interceptação da radiação fotossinteticamente ativa (RFA) em vinhedos de 'Moscato Giallo', com e sem cobertura plástica sobre o dossel vegetativo. O experimento foi conduzido no município de Flores da Cunha, na “Serra Gaúcha” (2906’S, 51²0’W, $541 \mathrm{~m})$, na safra de 2005/2006. Consistiu de fileiras de plantas descobertas e cobertas com filme de polietileno de baixa densidade transparente com $160 \mu \mathrm{m}$ de espessura. Foram feitas medições contínuas de RFA em diferentes alturas do dossel, nos dois sistemas. O índice de área foliar (IAF) foi determinado por método não destrutivo, tendo-se ajustado modelos relacionando IAF com graus-dia acumulados. Também foram ajustados modelos relacionando a eficiência de interceptação de RFA com IAF, nos vinhedos cobertos e descobertos. A cobertura plástica promoveu aumento de $12 \%$ na eficiência de interceptação da radiação pelo vinhedo. O vinhedo coberto apresentou menor coeficiente de extinção de RFA que em céu aberto.

Termos para indexação: Videira, plasticultura, radiação fotossinteticamente ativa, microclima.

\section{INTERCEPTION PATTERS OF SOLAR RADIATION IN VINEYARDS WITH AND WITHOUT PLASTIC COVERING}

\begin{abstract}
The study aimed to evaluate interception patterns of photosynthetically active radiation (PAR) in vineyards (Vitis vinifera cv. 'Moscato Giallo'), with and without plastic covering over the vegetative canopy. An experiment was carried out in Flores da Cunha, Rio Grande do Sul state, Brazil (29 $06^{\circ}$ S, $51^{\circ} 20^{\prime} \mathrm{W}, 541 \mathrm{~m}$ ) during the 2005/2006 growing season. It comprised uncovered and covered rows of plants by using a transparent $160 \mu \mathrm{m}$ thick plastic film (low density polyethylene). Continuing measurements of PAR were taken at different levels of the canopy in both treatments. The leaf area index (LAI) was determined by a non-destructive method along the crop cycle, and regression models relating LAI to the accumulated degree-days were adjusted. Regression models were also adjusted in order to estimate the intercepted PAR as function of LAI by covered and uncovered vineyards. The plastic covering over the vineyard promoted an increment of $12 \%$ for the interception efficiency of PAR. The covered vineyard showed a lower extinction coefficient for PAR than in open sky.
\end{abstract}

Index terms: grapes, plasticulture, photosynthetically active radiation, microclimate.

\footnotetext{
${ }^{1}$ (Trabalho 051-09). Recebido em: 18-02-2009. Aceito para publicação em: 25-09-2009.

${ }^{2}$ Eng. Agrônoma, Doutoranda do PPG Fitotecnia, Faculdade de Agronomia, UFRGS, Av. Bento Gonçalves, 7712, CEP: 91540-000, Porto Alegre-RS. e-mail: loanacardoso@gmail.com - Bolsista CNPq

${ }^{3}$ Eng. Agrônomo, Prof. Doutor, Dep. Plantas Forrageiras e Agrometeorologia, Faculdade de Agronomia, UFRGS, Av. Bento Gonçalves, 7712, CEP: 91540-000, Porto Alegre-RS. e-mail: homerobe@ufrgs.br - Bolsista CNPq

${ }^{4}$ Eng. Agrônoma, Mestranda do PPG Fitotecnia, Faculdade de Agronomia, UFRGS, Av. Bento Gonçalves, 7712, CEP: 91540-000, Porto Alegre-RS. e-mail: flaviacomiran@gmail.com - Bolsista CNPq

${ }^{5}$ Eng. Agrônomo, Doutorando do PPG Fitotecnia, Faculdade de Agronomia, UFRGS, Av. Bento Gonçalves, 7712, CEP: 91540-000, Porto Alegre-RS. e-mail: geraldochavarria@hotmail.com - Bolsista CNPq

${ }^{6}$ Eng. Agrônomo, Prof. Doutor, Depto de Horticultura e Silvicultura, Faculdade de Agronomia, UFRGS, Av. Bento Gonçalves, 7712 , CEP: 91540-000, Porto Alegre-RS. e-mail: marodin@ufrgs.br

${ }^{7}$ Eng. Agrônomo, Doutor, Pesquisador Centro Nacional de Pesquisa de Trigo, EMBRAPA, Rodovia BR 285, Km 294, CEP: 99001970, Passo Fundo-RS. e-mail: dalmago@cnpt.embrapa.br

${ }^{8}$ Eng. Agrônomo, Doutor, Pesquisador Embrapa Uva e Vinho, EMBRAPA, Rua Livramento, 515, Caixa Postal 130, CEP: 95700-000, Bento Gonçalves-RS. e-mail: henrique@cnpuv.embrapa.br - mandelli@cnpuv.embrapa.br
} 


\section{INTRODUÇÃO}

O cultivo protegido tem sido uma alternativa de manejo para a redução dos impactos climáticos na produção vitícola no Sul do Brasil. Ele promove mudanças na estrutura e na fisiologia das plantas, alterando as condições térmicas e hídricas do sistema solo-planta-atmosfera e os padrões de distribuição da radiação solar no dossel (Cardoso et al., 2008; Chavarria et al., 2008; Chavarria et al., 2009). Consequentemente, modificam-se os parâmetros descritivos das relações entre os fluxos de radiação e as características do dossel. Esses parâmetros necessitam ser ajustados adequadamente para alimentar sistemas de modelagem e tomadas de decisão sob este novo sistema de manejo em culturas frutíferas. Segundo Sinclair \& Seligman (1996), os modelos tendem a melhorar sua capacidade de predição à medida que aumenta o detalhamento descritivo do funcionamento das relações entre planta e ambiente.

A disponibilidade de radiação solar no interior de ambientes protegidos é diminuída em relação ao ambiente externo, devido à reflexão e à absorção pela cobertura. Na utilização de plástico do tipo ráfia em vinhedos, a transmissividade à radiação fotossinteticamente ativa (RFA) ao dossel coberto é da ordem de 67\% (Cardoso et al., 2008). Além disso, a absorção de radiação solar pelas folhas pode ser influenciada pelo sistema de condução e manejo (Smart et al., 1985). Em vinhedo da cultivar Itália conduzida em latada (tipo caramanchão) sem cobertura plástica, na região de Petrolina, Teixeira \& Lima Filho (1997) verificaram que a RFA transmitida pelo dossel vegetativo ao nível dos cachos diminuiu de $87 \%$ para $34 \%$, devido ao crescimento do índice de área foliar. Os efeitos da interceptação da radiação solar pelo dossel são determinantes da produtividade e da qualidade das uvas (Embrapa, 2003).

Aradiação tende a decrescer exponencialmente no perfil do dossel, com o aumento do índice de área foliar a partir do topo do dossel (Pandolfo, 1995). Por isto, a eficiência de interceptação de RFA(razão entre RFA interceptada e RFA incidente) aumenta com o crescimento da área foliar, estabilizando quando é atingido o máximo índice de área foliar (Müller \& Bergamaschi, 2005). Por outro lado, culturas com folhas predominantemente eretas tendem a ter baixo coeficiente de extinção de radiação solar ao contrário de folhas horizontais (Lambers et al., 1998). Baixos coeficientes de extinção de radiação são mais efetivos na transmissão da radiação para o interior e através do dossel, podendo proporcionar melhor aproveitamento da energia incidente.
A estimativa da capacidade produtiva das culturas e dos efeitos de mudanças nas técnicas de cultivo está entre as principais aplicações de modelos agrometeorológicos e de simulação de cultivos. É sabido que cultivos em ambientes protegidos provocam alterações em características do dossel (como a área foliar), que podem modificar os padrões de interceptação da radiação e o coeficiente de extinção da radiação. Assim, este trabalho teve por objetivo avaliar alterações nos padrões de interceptação e distribuição da radiação fotossinteticamente ativa em vinhedos conduzidos sob cobertura plástica.

\section{MATERIAL E MÉTODOS}

O estudo foi conduzido em área da Vinícola Giacomin, no município de Flores da Cunha-RS (2906'S, 5120’W, $541 \mathrm{~m})$, na "Serra Gaúcha", durante a safra de 2005/2006. Utilizou-se um vinhedo de sete anos, com a cultivar 'Moscato Giallo' (clone VCR 1) sobre porta-enxerto Kobber 5BB, destinada à produção de vinhos brancos. $\mathrm{O}$ mesmo foi estabelecido com 3.700 plantas por hectare, distribuídas em fileiras, cuja vegetação era disposta em cortinas inclinadas em sistema de condução com formato de "Y". Suportes de concreto no formato de $\mathrm{Y}$, com haste de $1,10 \mathrm{~m}$ de altura e braços laterais de $0,8 \mathrm{~m}$, unidos por fios de arame liso, davam sustentação ao vinhedo. Em 01-09-2005 foi realizada a poda seca em sistema misto. Em cada planta, foram deixadas quatro varas com quatro a cinco gemas, além de sete a dez esporões de duas gemas. Durante o ciclo vegetativo/produtivo, efetuou-se o desponte, em 04-11-05, mantendo-se os ramos dentro do sistema de condução.

O delineamento consistiu em duas áreas contíguas que representaram os tratamentos: com e sem cobertura plástica. A área sem cobertura era composta por cinco fileiras de plantas, enquanto a área coberta tinha doze fileiras. Cada fileira continha 40 plantas, com espaçamento de $0,9 \mathrm{~m}$ na linha e $3,0 \mathrm{~m}$ nas entrelinhas. As avaliações foram realizadas em 10 plantas previamente marcadas em cada uma das áreas. Para a cobertura, utilizou-se um filme plástico transparente de polietileno de baixa densidade, tipo ráfia, com aditivos antiUV e antigotejo e espessura de $160 \mu \mathrm{m}$. Toda a área experimental havia sido coberta na safra anterior (2004/2005) com o mesmo tipo de plástico. Antes da poda, o plástico foi retirado das cinco fileiras que constituíram o tratamento sem cobertura (testemunha). Braços de madeira, aparafusados nas extremidades de cada suporte em "Y", formavam uma cumeeira em "V" invertido, para sustentar a cobertura plástica a $2,4 \mathrm{~m}$ acima do 
solo. A largura da cobertura era de $2,40 \mathrm{~m}$ entre suas bordas laterais.

Logo após a poda, foram instalados sensores para monitorar o microclima em diferentes níveis, nos dois tratamentos, tais como temperatura e umidade do ar, velocidade do vento e radiação fotossinteticamente ativa (detalhes sobre medições e alteração de microclima estão em Cardoso et al., 2008). A radiação fotossinteticamente ativa (RFA, 400-700nm) foi medida com sensores providos de cinco células fotovoltaicas, nas seguintes posições: acima da cobertura plástica, entre a cobertura e o dossel, acima do dossel descoberto e junto aos cachos de ambos os tratamentos. Os sensores foram conectados a dataloggers Campbell CR21X com leituras a cada 30 s e médias armazenadas a cada $30 \mathrm{~min}$. Junto ao experimento, instalou-se uma estação meteorológica automática para avaliar as condições locais.

$\mathrm{O}$ índice de área foliar (IAF) foi determinado de forma não destrutiva, pelo método descrito por Carbonneau (1976), em que a área de cada folha é calculada a partir da soma do comprimento das duas nervuras laterais. Para a calibração do método, foram coletadas 100 folhas por tratamento, e sua área foi medida em planímetro eletrônico LI-COR, modelo LI 3000. Foram realizadas contagens de folhas das plantas marcadas, semanalmente, e medidas as nervuras principais de 10 folhas por planta, a cada 15 dias. A área média das folhas, calculada através da soma das nervuras, foi multiplicada pelo número de folhas por planta, para estimar a área foliar média por planta e posterior estimativa de IAF. Com os valores de IAF de cada tratamento, foram ajustados modelos matemáticos relacionando sua evolução com graus-dia acumulados, nas duas condições: coberto e descoberto. Valores diários de índice de área foliar, ajustados por graus-dia acumulados, foram utilizados para descrever a distribuição da radiação solar no dossel.

O cálculo de graus-dia acumulados após a poda foi feito segundo equações propostas por Villa Nova et al. (1972), tomando-se $10^{\circ} \mathrm{C}$ como temperatura-base inferior para videira, segundo Pedro Júnior et al. (1994).

Para os dois tratamentos, a radiação fotossinteticamente ativa interceptada $\left(\mathrm{RFA}_{\text {int }}\right) \mathrm{e}$ absorvida $\left(\mathrm{RFA}_{\mathrm{abs}}\right)$ pela cultura foi calculada pelas equações propostas por Varlet-Grancher et al. (1989):

$\mathrm{RFA}_{\text {int }}=\mathrm{RFA}_{\mathrm{inc}}-\mathrm{RFA}_{\mathrm{t}}$

sendo $\mathrm{RFA}_{\mathrm{inc}}$ a radiação fotossinteticamente ativa incidente, medida sobre o dossel, e RFA a radiação fotossinteticamente ativa transmitida pela cultura, medida ao nível do solo.

$\mathrm{RFA}_{\mathrm{abs}}=\mathrm{RFA}_{\mathrm{inc}}+\mathrm{RFA}_{\mathrm{rs}}-\mathrm{RFA}_{\mathrm{rsc}}-\mathrm{RFA}_{\mathrm{t}}$

sendo RFA $_{\text {rs }}$ a radiação fotossinteticamente ativa refletida pelo solo, medida ao nível do solo, e RFA a radiação fotossinteticamente ativa refletida pelo solo e cultura, medida acima do dossel.

Em ambos os tratamentos, a eficiência de interceptação da radiação fotossinteticamente ativa pela cultura $\left(\varepsilon_{\text {int }}\right)$ foi estimada pelo quociente entre a radiação fotossinteticamente ativa interceptada e $o$ total incidente sobre o dossel, na forma de:

$\varepsilon_{\text {int }}=\mathrm{RFA}_{\mathrm{int}} / \mathrm{RFA}_{\mathrm{inc}}$

A partir de valores de eficiência de interceptação de RFA e IAF, foi estimado o coeficiente de extinção (k) do dossel, em ambos os tratamentos, por regressão linear. O coeficiente de extinção para RFA corresponde ao parâmetro angular da função linear $(b)$, derivada da lei de Beer, adaptada por Monsi \& Saeki (1953).

$\ln \left(1-\varepsilon_{\text {int }}\right)=-$ b.IAF

A radiação disponível à cultura é aquela que incide sobre a mesma. Desta forma, no tratamento coberto, foi considerada como RFA incidente sobre o dossel coberto aquela que atravessou a cobertura plástica, medida logo acima das plantas, entre a cobertura e o dossel.

\section{RESULTADOS E DISCUSSÃO}

O índice de área foliar (IAF) apresentou evolução semelhante nos dois tratamentos com crescimento inicial lento, atingindo um patamar praticamente constante até a colheita. Houve decréscimo mais acentuado de IAF no final do ciclo no vinhedo descoberto, em função da rápida senescência das folhas, enquanto o vinhedo coberto manteve as folhas por um tempo maior (Figura 1). A manutenção das folhas por um período mais longo permite maior acúmulo de reservas para a safra seguinte, em função da manutenção dos processos fotossintéticos (Chavarria et al., 2008).

As equações que melhor se ajustaram à variação de IAF, em função de graus-dia, indicam tendências diferenciadas. Para o vinhedo coberto, o modelo que melhor se ajustou à função IAF $\mathrm{x}$ grausdia acumulados foi log-normal com três parâmetros, 
enquanto para o vinhedo descoberto um modelo gaussiano com três parâmetros foi o que apresentou melhor ajuste (Figura 1). No vinhedo descoberto, houve rápido crescimento foliar até cerca de 1.000 graus-dia, atingindo IAF máximo ajustado de 4,5, voltando a decrescer rapidamente em função da senescência foliar. $\mathrm{O}$ máximo IAF observado foi de 4,5 em 1.100 graus-dia, igualando-se ao valor ajustado. No vinhedo coberto, houve, também, rápido crescimento até aproximadamente 1.000 graus-dia, mantendo IAF máximo de 3,6, entre 900 e 1.300 graus-dia. O máximo valor de IAF observado na área coberta foi de 3,9 em 1.500 graus-dia, estando próximo de 3,6, que foi o valor máximo ajustado (Figura 1). Embora sem comparação estatística, verifica-se que o modelo aplicado ao vinhedo coberto descreve melhor a manutenção de IAF na etapa mediana do ciclo e o lento decréscimo da área foliar ao término do ciclo produtivo.

Embora as equações matemáticas não consigam abranger toda gama de respostas fisiológicas das plantas, o IAF ajustado apresentou estreita associação com valores observados (Figura 2). Tanto no tratamento coberto quanto no descoberto, o IAF ajustado apresentou alta correlação com valores observados, ficando próximo à relação $1: 1$, e com coeficientes de determinação de 0,84 e 0,92 para vinhedos coberto e descoberto, respectivamente. $\mathrm{Na}$ área coberta (Figura 2A), os valores estimados apresentaram maior dispersão, especialmente quando IAF foi inferior a $2 . \mathrm{Na}$ área descoberta, verificou-se melhor ajuste, sendo IAF ajustado próximo ao observado, com pequena dispersão de pontos ao longo de todo o período (Figura 2B). É possível que a poda verde feita no vinhedo coberto, necessária para que os ramos se mantivessem debaixo da cobertura plástica, tenha interferido na evolução do IAF, limitando seu pico máximo no meio do ciclo e afetando sua relação com o acúmulo de graus-dia. Muito embora esta ressalva, os resultados indicam que modelos podem ser utilizados para estimar o índice de área foliar a partir do somatório de graus-dia, na cultivar 'Moscato Giallo', conduzida tanto em céu aberto como sob cobertura plástica.

No cálculo da radiação fotossinteticamente ativa interceptada pelos dois vinhedos, verificouse que o dossel coberto interceptou cerca de $30 \%$ menos radiação que o descoberto (Figura 3). Padrão semelhante ocorreu com a radiação fotossinteticamente ativa absorvida pelo dossel. Esta diferença é atribuída, sobretudo, à menor incidência de RFA sobre o vinhedo coberto, que foi da ordem de $67 \%$ da radiação incidente externamente (Cardoso et al., 2008). Além disso, observou-se que o dossel coberto teve menor refletividade e menor transmissão de radiação ao solo que o descoberto.

A eficiência de interceptação é função, principalmente, da área foliar disponível para captação da radiação, do ângulo foliar e da distribuição das folhas no dossel (Gallagher \& Biscoe, 1978). Em média, a eficiência de interceptação foi $12 \%$ superior na área coberta em relação à descoberta, considerando RFA incidente sobre cada dossel (Figura 4). Observou-se aumento da eficiência de interceptação de RFA até cerca de 500 ou 600 grausdia, atingindo valores máximos de aproximadamente 0,85 na área coberta e 0,82 na área descoberta. A partir de 700 graus-dia, houve pequeno decréscimo na eficiência de interceptação, a qual se manteve em torno de 0,7 até 1.800 graus-dia, para ambos os tratamentos. No final do ciclo, houve decréscimo da eficiência de interceptação de RFA, o qual foi mais rápido no vinhedo descoberto em função da maior senescência das folhas, ocasionada por fatores bióticos e abióticos (Figura 4).

A eficiência de interceptação da radiação fotossinteticamente ativa não se ajustou ao modelo exponencial obtido em outras culturas, como milho (Müller \& Bergamaschi, 2005) e tomateiro (Radin et al., 2003). Para ambos os tratamentos, a evolução da eficiência de interceptação apresentou melhor ajuste ao modelo sigmoidal. A Figura 5 demonstra que o aumento da eficiência de interceptação da RFA, em função do índice de área foliar, apresentou tendências semelhantes nos vinhedos cobertos e descobertos, porém diferindo em inclinação e no IAF correspondente à máxima eficiência de interceptação.

$\mathrm{Na}$ área coberta, a máxima eficiência de interceptação ajustada foi de $0,84\left(\mathrm{R}^{2}\right.$ de 0,94$)$ quando foi atingido o máximo IAF. O padrão observado foi semelhante ao ajustado, onde a máxima eficiência $(0,85)$ somente foi atingida quando a cultura apresentava máximo IAF, próximo a 3,5. O vinhedo coberto teve menor IAF que o descoberto e atingiu a máxima eficiência de interceptação de RFA somente com IAF máximo, a partir do qual houve estabilização da eficiência (Figura 5A).

Em IAF baixo, próximo a 1, a interceptação de RFA no vinhedo coberto apresentou pequena diferença em relação ao descoberto. A partir de IAF 2, a eficiência de interceptação do dossel coberto foi inferior àquela da área descoberta, até que fosse atingida a máxima interceptação de radiação (Figura $5 \mathrm{~A})$. Isto pode ser atribuído à maior disponibilidade de radiação difusa no vinhedo coberto. Por ser multidirecional, a radiação difusa penetra mais no 
dossel, resultando em diminuição da eficiência de interceptação pela cultura. Vários autores demonstraram que a radiação difusa é maior debaixo de cobertura plástica que em ambiente externo. Em Pelotas-RS, Farias et al. (1993) e Camacho et al. (1995) verificaram que ela foi $45 \%$ superior no interior de estufas plásticas que no ambiente externo, na maior parte do período experimental.

$\mathrm{Na}$ área descoberta, a maior inclinação da curva de eficiência entre IAF 1 e 2 indica maior eficiência nesse período em relação ao vinhedo coberto. A máxima eficiência de interceptação ajustada foi de 0,72 no vinhedo descoberto $\left(\mathrm{R}^{2}\right.$ de 0,92$)$, embora com maior dispersão de pontos em relação ao dossel coberto. No vinhedo descoberto, houve aumento da eficiência de interceptação de RFA até IAF próximo a 2,5. O valor máximo observado neste tratamento foi 0,82 e também ocorreu antes de IAF máximo. Em IAF próximo a 3, o dossel cobria grande parte do solo, tendendo à estabilização da eficiência de interceptação, embora a área foliar ainda estivesse em crescimento (Figura 5B).

$\mathrm{O}$ coeficiente de extinção $(\mathrm{k})$ do vinhedo coberto foi de $0,44\left(\mathrm{R}^{2}=0,89\right)$, enquanto na área descoberta $\mathrm{o}$ coeficiente de extinção foi de $0,49\left(\mathrm{R}^{2}=0,73\right)$ (Figura 6). Com tomateiro, Radin et al. (2002) também obtiveram maior coeficiente de extinção de RFA em céu aberto que debaixo de cobertura plástica, embora com valores ligeiramente superiores, o que pode ser atribuído a diferenças na arquitetura foliar e no arranjo de plantas. Para o tratamento descoberto, houve dispersão nos valores de eficiência de interceptação de RFA, praticamente em todo o período, enquanto na área coberta a dispersão evidenciou-se somente a partir de IAF próximo ao máximo. O menor coeficiente de extinção na área coberta indica que, para um mesmo IAF, uma fração maior de radiação ultrapassou o dossel e foi transmitida até o solo, em comparação ao vinhedo descoberto. A maior disponibilidade de radiação difusa sobre o vinhedo coberto pode explicar esta diferença, uma vez que, por ser multidirecional, ela tem maior transmissão nas camadas de folhas, podendo chegar até o solo (Farias et al., 1993; Radin et al., 2002).

Esses valores de coeficiente de extinção podem ser considerados baixos em comparação a outros cultivos, em função da arquitetura de folhas e do arranjo de plantas, que influenciam no padrão de extinção de RFA. Müller \& Bergamaschi (2005) obtiveram coeficiente de extinção de 0,70 na cultura do milho, em alta população de plantas e com IAF acima de 2,7. Também em milho, Kunz et al. (2007) observaram aumento do coeficiente de extinção, de 0,54 para 0,75 , pela redução do espaçamento de
$0,80 \mathrm{~m}$ para $0,4 \mathrm{~m}$ entre fileiras de plantas.

Com tomateiro, Radin (2002) obteve um coeficiente de extinção médio de 0,57 em estufa plástica. O tomateiro tem folhas grandes e predominantemente horizontais, com elevada interceptação de radiação por unidade de área foliar. Esses baixos valores observados por Radin (2002) foram atribuídos à arquitetura foliar e à distribuição das plantas em linhas duplas, que propiciaram maior espaçamento entre os pares de linhas. Segundo os autores, este arranjo de plantas diminui a eficiência de interceptação do tomateiro, permitindo que grande parte de RFA seja transmitida ao solo, provocando redução no coeficiente de extinção. Assim, os baixos valores de coeficiente de extinção encontrados no presente trabalho também podem ser explicados pelo padrão de distribuição das plantas, pois o vinhedo apresenta espaçamento amplo entre fileiras, o que permitiu grande incidência de RFA ao nível do solo, especialmente nas entrelinhas. 


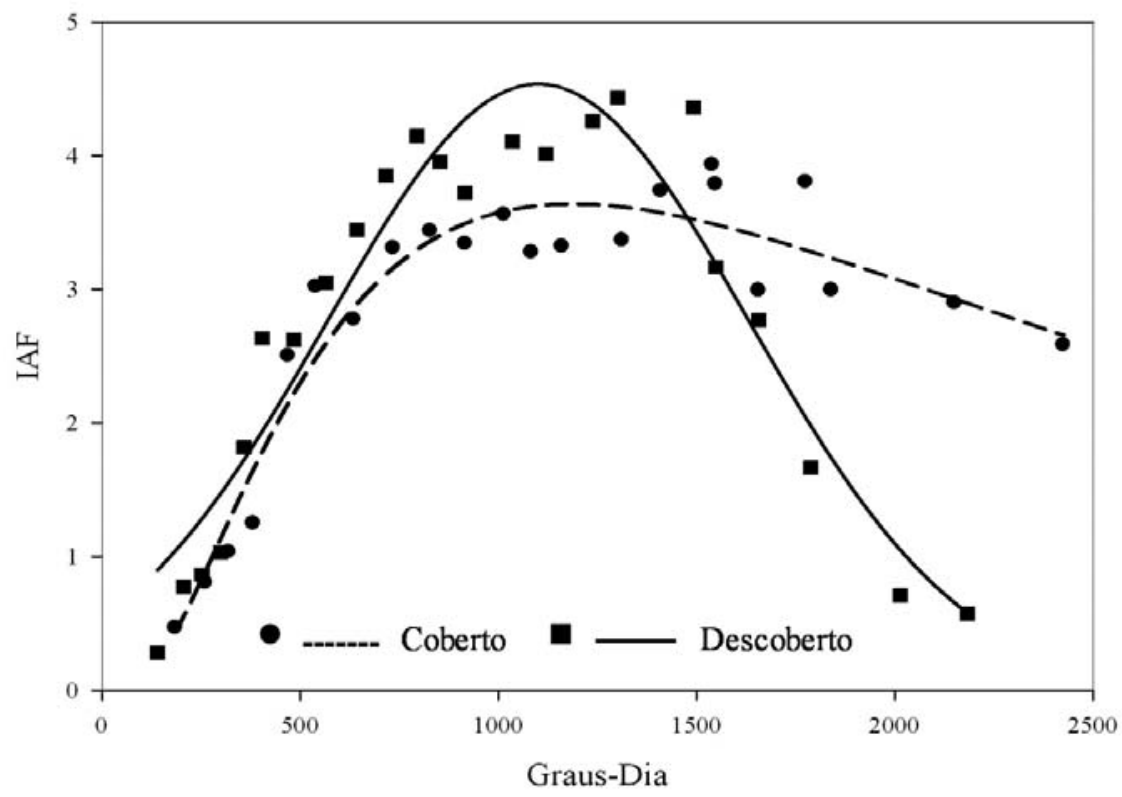

$$
\begin{array}{ll}
\text { IAF Coberto }=3,64 \exp \left\{-0,5\left[\operatorname{Ln}\left(\mathrm{GD}_{\mathrm{acm}} / 1186,30\right) / 0,901\right]^{2}\right\} & \mathrm{R}_{\text {ajustado }}^{2}=0,91 \\
\text { IAF Descoberto }=4,54 \exp \left\{-0,5\left[\left(\mathrm{GD}_{\mathrm{acm}}-1100,44\right) / 533,81\right]^{2}\right\} & \mathrm{R}_{\text {ajustado }}=0,91
\end{array}
$$

FIGURA 1- Índice de área foliar (IAF) observado (• a) e ajustado (----; - ) em função de graus-dia acumulados, em vinhedos de 'Moscato Giallo' com (Coberto) e sem cobertura plástica (Descoberto). Flores da Cunha-RS, 2005/2006.

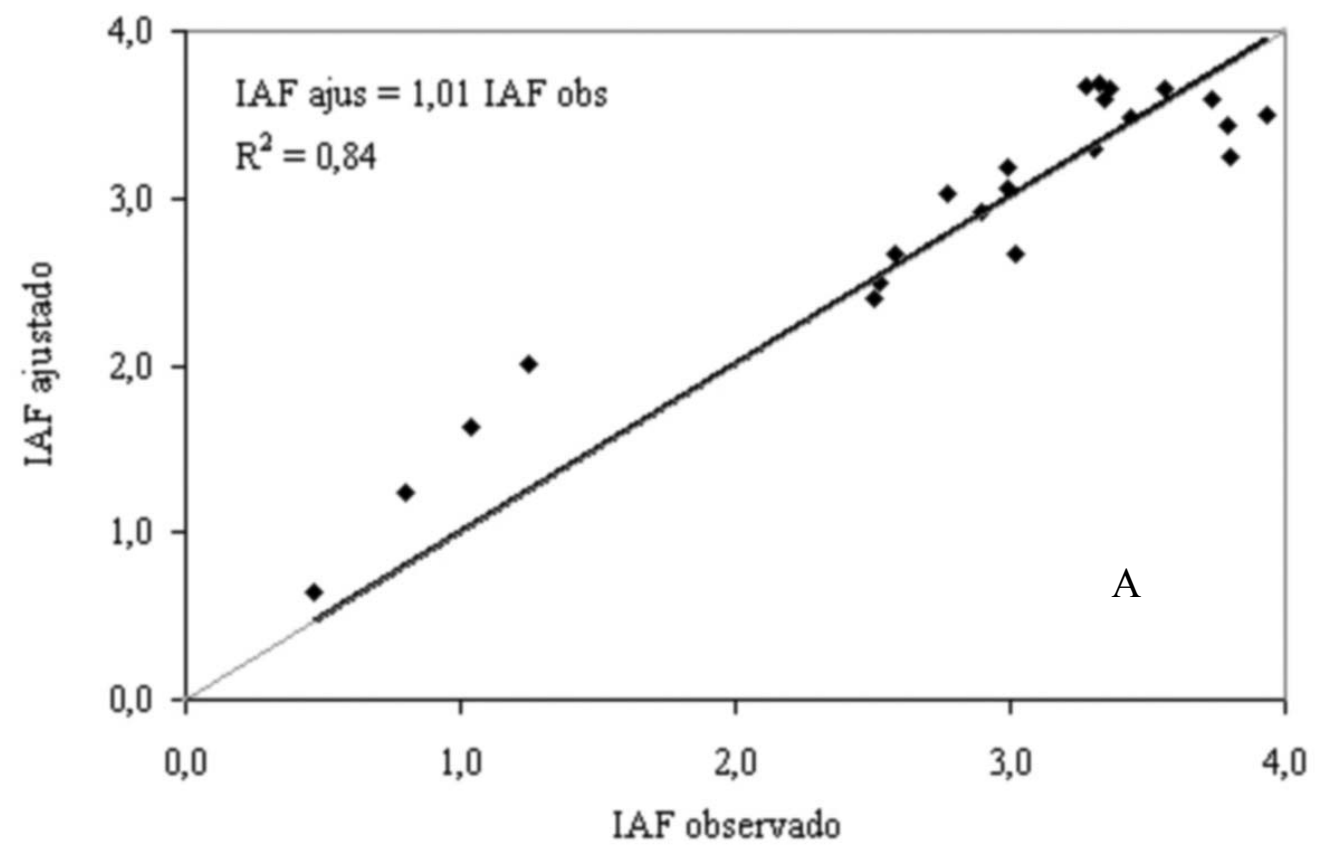

continua 


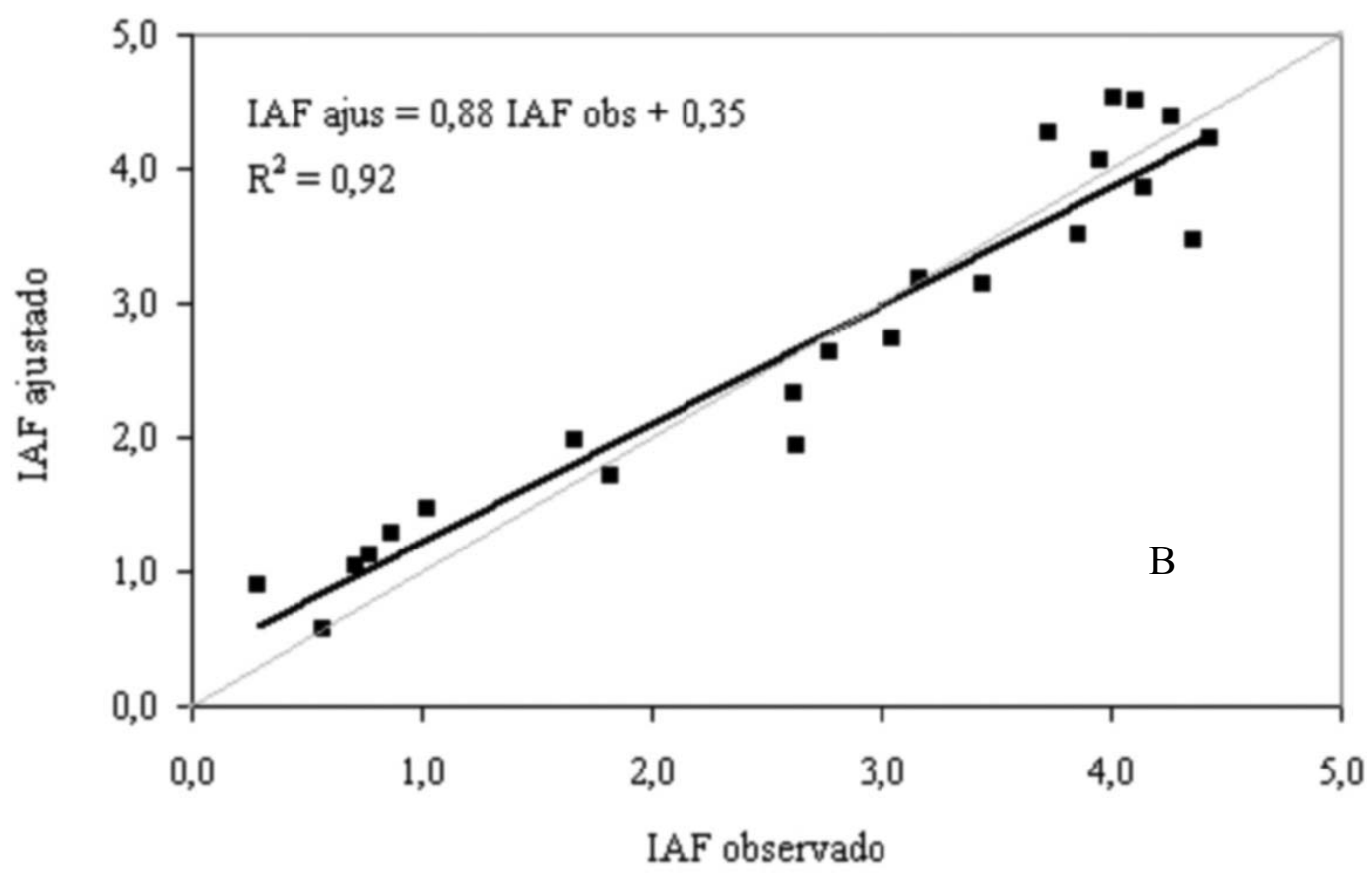

FIGURA 2-Relação entre o índice de área foliar (IAF) observado e ajustado em função de graus-dia acumulados, em vinhedos de 'Moscato Giallo' com (A) e sem cobertura plástica (B). Flores da Cunha-RS, 2005/2006.

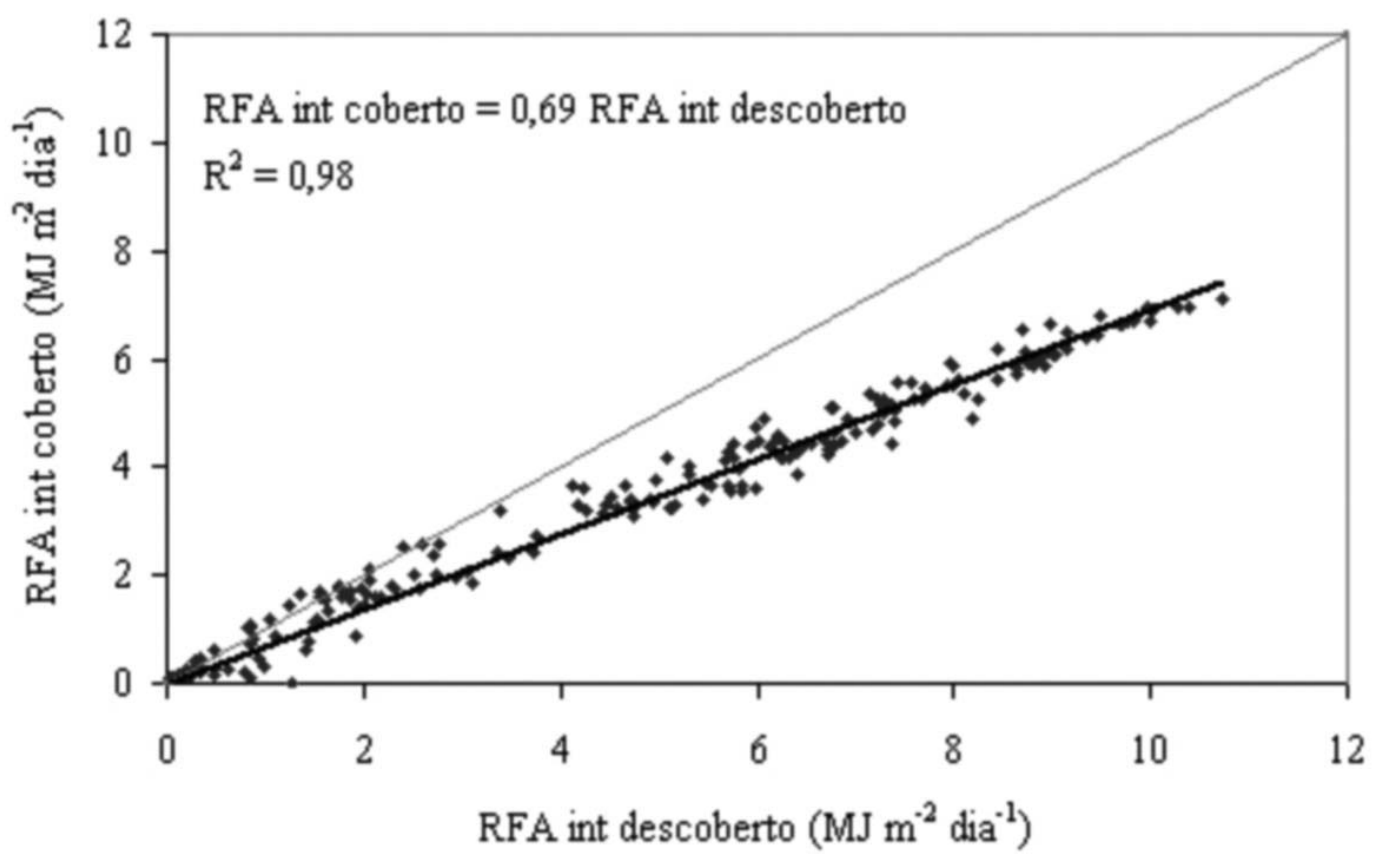

FIGURA3- Relação entre radiação fotossinteticamente ativa interceptada, em vinhedos de 'Moscato Giallo' com (Coberto) e sem cobertura plástica (Descoberto). Flores da Cunha- RS, 2005/2006. 


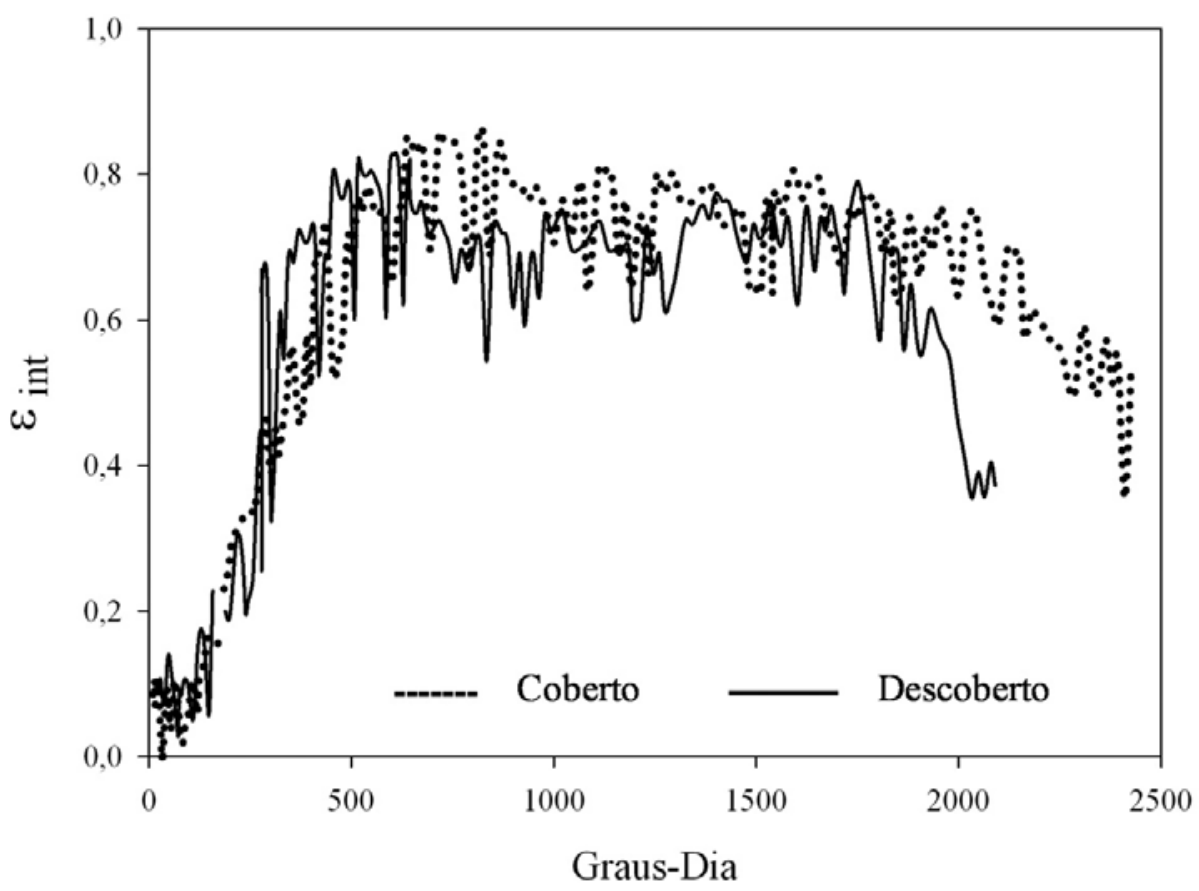

FIGURA 4- Eficiência de interceptação da radiação fotossinteticamente ativa $\left(\varepsilon_{\text {int }}\right)$ em função de grausdia acumulados, em vinhedos de 'Moscato Giallo' com (Coberto) e sem cobertura plástica (Descoberto). Flores da Cunha-RS, 2005/2006.

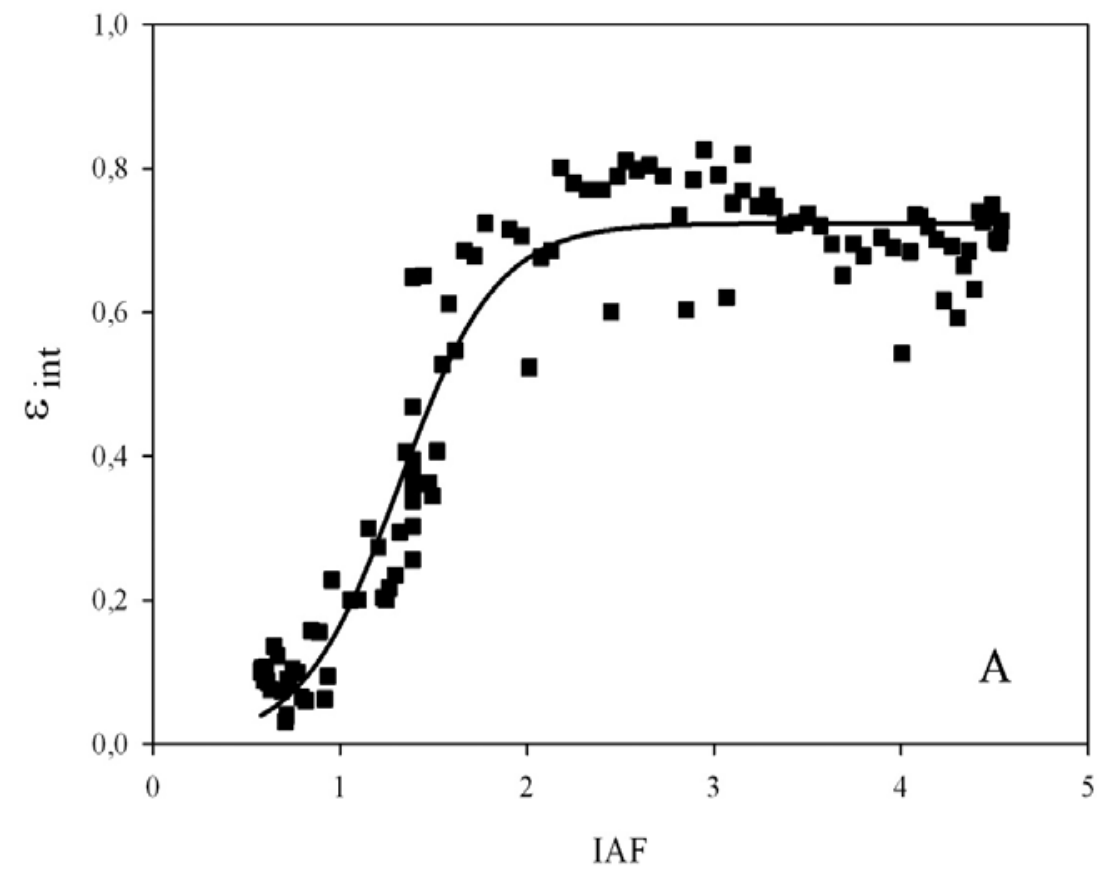

$\mathcal{E}$ int $=0,72 /\left\{1+\mathrm{e}^{[-(\mathrm{IAF}-1,318) / 0,261]}\right\} \quad \mathrm{R}_{\text {ajustado }}^{2}=0,92$ 


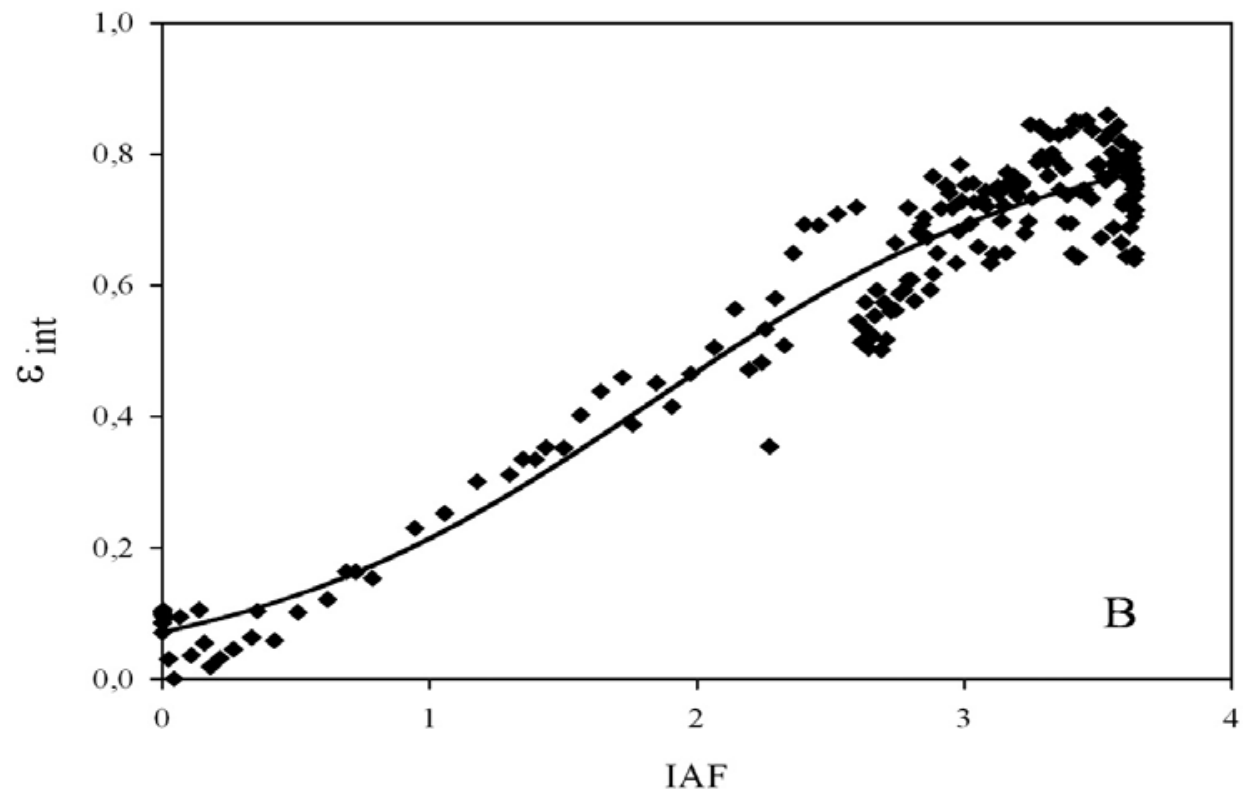

$\varepsilon$ int $=0,84 /\left\{1+\mathrm{e}^{[-(\mathrm{IAF}-1,831) / 0,771]}\right\} \quad \mathrm{R}^{2}$ ajustado $=0,94$

FIGURA 5- Eficiência de interceptação $\left(\varepsilon_{\text {int }}\right)$ da radiação fotossinteticamente ativa em função do índice de área foliar, em vinhedos de 'Moscato Giallo' com (A) e sem cobertura plástica (B). Flores da Cunha-RS, 2005/2006.

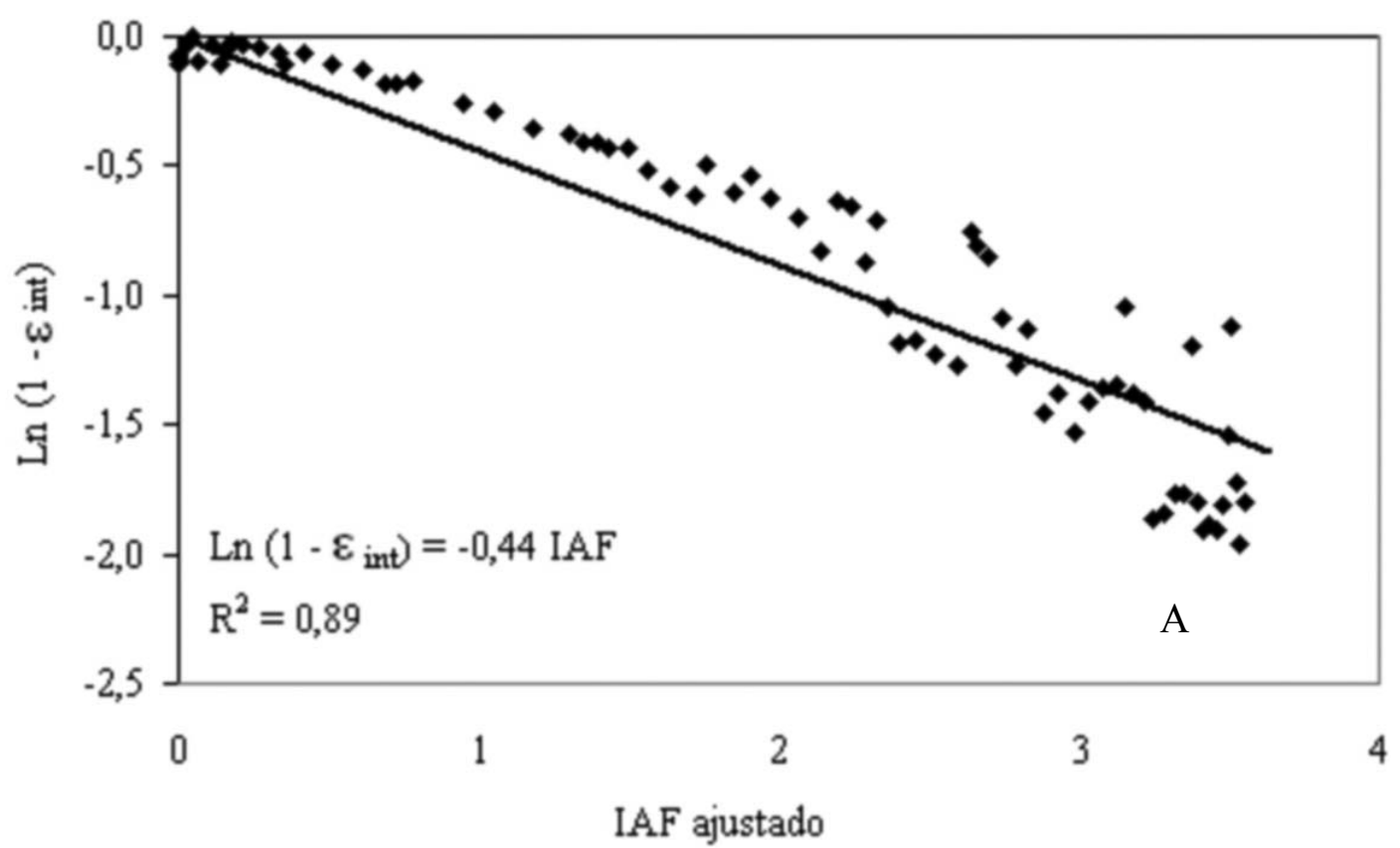




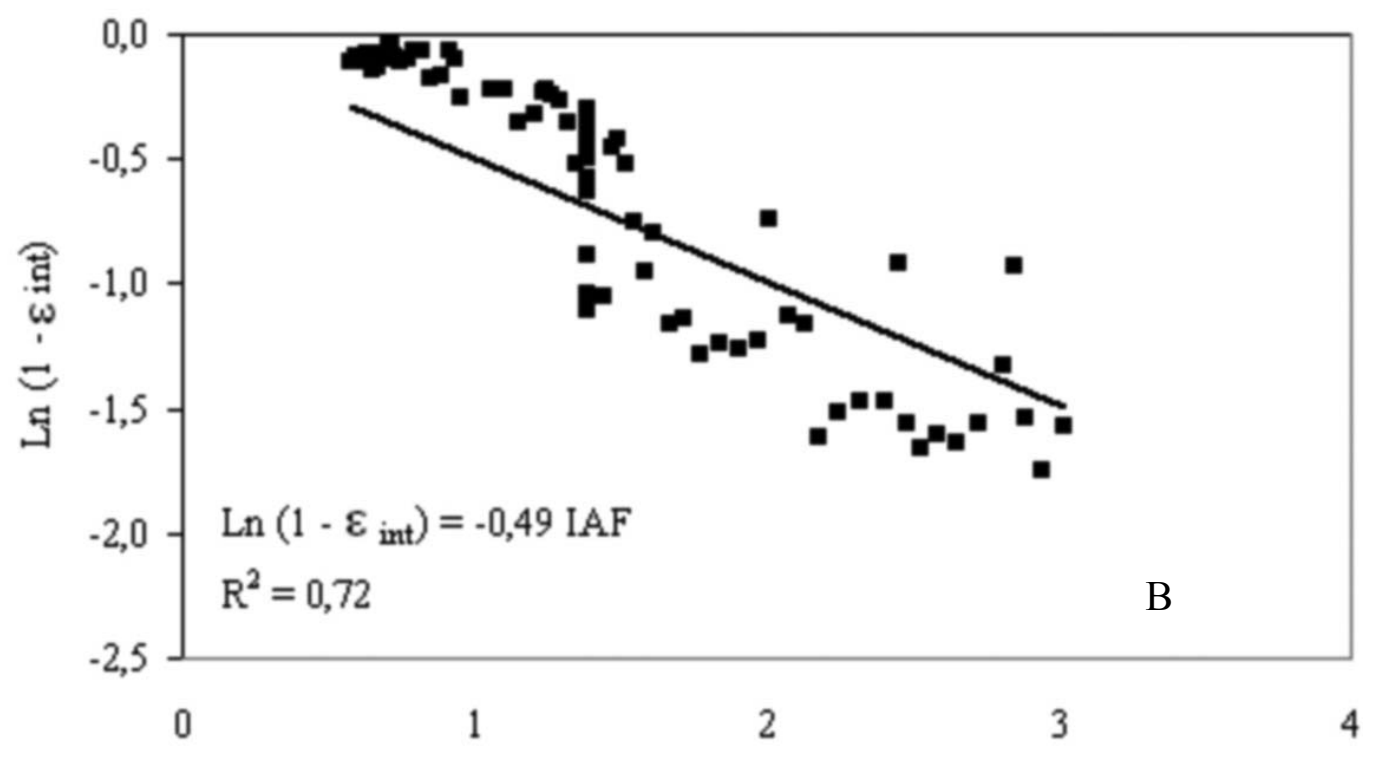

IAF ajustado

FIGURA 6- Estimativa do coeficiente de extinção para radiação fotossinteticamente ativa (parâmetro b da regressão), em função do índice de área foliar ajustado em função de graus-dia acumulados, em vinhedos de 'Moscato Giallo' com (A) e sem cobertura plástica (B). Flores da Cunha-RS, 2005/2006.

\section{CONCLUSÕES}

1-O emprego de cobertura plástica sobre vinhedos altera os padrões de interceptação e distribuição da radiação fotossinteticamente ativa e, consequentemente, os parâmetros descritivos das relações entre os fluxos de radiação e as características do dossel vegetativo.

2-Considerando a radiação solar incidente ao nível do dossel vegetativo, a cobertura plástica sobre vinhedos promove aumento da eficiência de interceptação da radiação fotossinteticamente ativa pelo dossel.

3-O coeficiente de extinção de radiação solar da videira é menor sob cobertura plástica que em céu aberto. Isto significa que, para um mesmo índice de área foliar, há menor interceptação de radiação solar pelo vinhedo coberto que em céu aberto.

\section{REFERÊNCIAS}

CAMACHO, M. J.; ASSIS, F. N.; MARTINS, S. R.; MENDEZ, M. E. G. Avaliação de elementos meteorológicos em estufa plástica em Pelotas-RS. Revista Brasileira de Agrometeorologia, Santa Maria, v.3, p.19-24, 1995.

CARDOSO, L. S.; BERGAMASCHI, H.; COMIRAN, F.; CHAVARRIA, G.; MARODIN, G. A. B.; DAlMAGO, G. A.; SANTOS, H. P dos.; MANDELLI, F. Alterações micrometeorológicas em vinhedos pelo uso de coberturas de plástico. Pesquisa Agropecuária Brasileira, Brasília, v.43, n.4, p.441-447, 2008.

CARBONnEAU, A. Príncipes et méthodes de mesure de la surface foliaire. Essai de caractérisations des types de feuilles dans genre Vitis. Annales De L'amélioration Des Plantes, Paris, v.26, p.327-43, 1976.

CHAVARRIA, G.; SANTOS, H. P. dos; FELIPPETO, J.; MARODIN, G. A. B.; BERGAMASCHI, H.; CARDOSO, L. S.; FIALHO, F. B. Relações hídricas e trocas gasosas em vinhedo sob cobertura plástica. Revista Brasileira de Fruticultura, Jaboticabal, v. 30, n. 4, p. 1022-1029, 2008. 
CHAVARRIA, G.; SANTOS, H. P. dos; MANDELLI, F.; MARODIN, G. A. B.; BERGAMASCHI, H.; CARDOSO, L. S. Caracterização fenológica e requerimento térmico da cultivar Moscato Giallo sob cobertura plástica. Revista Brasileira de Fruticultura, Jaboticabal, v. 31, n. 1, p. 119-126, 2009.

EMBRAPA. Uvas viníferas para processamento em regiões de clima temperado. 2003. Bento Gonçalves: EMBRAPA Uva e Vinho. Disponível em: <http://www.cnpuv.embrapa.br/publica/sprod/ UvasViniferasRegioesClimaTemperado $>$. Acesso em:18 jun. 2007.

FARIAS, J. R. B.; BERGAMASCHI, H.; MARTINS, S. R.; BERLATO, M. A. Efeito da cobertura plástica de estufa sobre a radiação solar. Revista Brasileira de Agrometeorologia, Santa Maria, v.1, n.1, p.3136, 1993.

GALLAGHER, J. N.; BISCOE, P. V. Radiation absorption, growth and yield of cereals. Journal Agricultural Science, Cambridge, v.91, p.47-60, 1978.

LAMBERS, H.; CHAPIN, F. S.; PONS, T. L. Plant physiological ecology. New York: Springer, 1998. $450 \mathrm{p}$.

KUNZ, J. H.; BERGONCI, J. I.; BERGAMASCHI, H.; DALMAGO, G. A.; HECKLER, B. M. M.; COMIRAN, F. Uso da radiação solar pelo milho sob diferentes preparos do solo, espaçamento e disponibilidade hídrica. Pesquisa Agropecuária Brasileira, Brasília, v. 42, n. 11, p. 1511-1520, 2007.

MONSI, M.; SAEKI, T. The light factor in plant communities and its significance for dry matter production. Japanese Journal of Botany, Tokyo, v.14, p.22-52, 1953.

MÜLLER, A. G.; BERGAMASCHI, H. Eficiências de interceptação, absorção e uso da radiação fotossinteticamente ativa pelo milho (Zea mays L.), em diferentes disponibilidades hídricas e verificação do modelo energético de estimativa da massa seca acumulada. Revista Brasileira de Agrometeorologia, Santa Maria, v. 13, n. 1, p. 27-33, 2005.

PANDOLFO, C. Parâmetros básicos para o uso na modelagem do rendimento de matéria seca em alfafa (Medicago sativa L.). 1995. 128 f. Dissertação
(Mestrado em Fitotecnia) - Faculdade de Agronomia, Universidade Federal do Rio Grande do Sul, Porto Alegre, 1995.

PEDRO JÚNIOR, M. J.; SENTELHAS, P. C.; POMMER, C. V.; MARTINS, F. P. Determinação da temperatura-base, graus-dia e índice Biometeorológico para a videira 'Niagara Rosada'. Revista Brasileira de Agrometeorologia, Santa Maria, v. 2, p. 51-56, 1994.

RADIN, B. Eficiência de uso da radiação fotossinteticamente ativa pela cultura do tomateiro em diferentes ambientes. 2002. $124 \mathrm{f}$. Tese (Doutorado em Fitotecnia) - Faculdade de Agronomia, Universidade Federal do Rio Grande do Sul, Porto Alegre, 2002.

RADIN, B.; BERGAMASCHI, H.; REISSER JUNIOR, C.; BARNI, N. A.; MATZENAUER, R.; DIDONÉ, I. A. Eficiência de uso da radiação fotossinteticamente ativa pela cultura do tomateiro em diferentes ambientes. Pesquisa Agropecuária Brasileira, Brasília, v. 38, n. 9, p. 1017-1023, 2003.

SINCLAIR, T.R.; SELIGMAN, N. G. Crop modeling: from infancy to maturity. Agronomy Journal, Madison, v. 88, p. 698-704, 1996.

SMART, R. E.; ROBINSON, J. B.; DUE, G. R.; BRIEN C J. Canopy microclimate modifications for the cultivar Shiraz. I. Definition of canopy microclimate. Vitis, Landau, v.24, p. 17-31, 1985.

TEIXEIRA, A. H. C. de ; LIMA FILHO, J. M. P. Relações entre o índice de área foliar e radiação solar na cultura da videira. Revista Brasileira de Agrometeorologia, Santa Maria, v. 5, n. 2, p. 143146, 1997.

VARLET-GRANCHER, C.; GOSSE, G.; CHARTIER, M.; SINOQUET, H.; BONHOMME, R.; ALLIRAND, J. M. Mise au point: rayonnement solaire absorbé ou intercepté par un couvert végétal. Agronomie, Paris, v.9, p.419-439, 1989.

VILLA NOVA, N. A.; PEDRO JUNIOR, M. J.; PEREIRA, A. R.; OMETTO, J. C. Estimativa de graus-dia acumulados acima de qualquer temperatura base em função das temperaturas máxima e mínima. Ciência da Terra, São Paulo, n.30, p.1-8, 1972. 